\title{
Comment and reply on "Palaeoenvironmental control on distribution of crinoids in the Bathonian (Middle Jurassic) of England and France" by Aaron W. Hunter and Charlie J. Underwood
}

Aaron W. Hunter and Charlie J. Underwood

Acta Palaeontologica Polonica 55 (1), 2010: 174-176 doi: http://dx.doi.org/10.4202/app.2010.0016

Mariusz A. Salamon, Przemysław Gorzelak, and Michał Zatoń (2010) have presented an interesting discussion of our paper. We would like to thank these authors for bringing the extensive work on crinoid systematics and palaeoecology from Eastern Europe (Pisera and Dzik 1979; Głuchowski 1987; Salamon et al. 2006, 2008; Salamon and Zatoń 2006, 2007; Salamon 2008a, b, c, 2009; Zatoń et al. 2008) to our attention. Some of this important data was inadvertently omitted from, or post-dated the acceptance of, Hunter and Underwood (2009).

Aaron W. Hunter [a.hunter@nhm.ac.uk], Department of Palaeontology, Natural History Museum, Cromwell Road, London, SW7 5BD UK; Charlie J.

Underwood [c.underwood@bbk.ac.uk], School of Earth and Planetary Science, Birkbeck College, University of London, Malet St, Bloomsbury, London, WC1E 7HX UK.

This is an open-access article distributed under the terms of the Creative Commons Attribution License (for details please see creativecommons.org), which permits unrestricted use, distribution, and reproduction in any medium, provided the original author and source are credited.

Faf Full text $(73.8 \mathrm{kB})$ 